Malicious Mind Readers? A Meta-Analysis on Machiavellianism and Cognitive and Affective Empathy

Christian Blötner, Ricarda Steinmayr, \& Sebastian Bergold TU Dortmund University

Personality and Individual Differences, accepted

This is an unedited manuscript accepted for publication. The manuscript will undergo copyediting, typesetting, and review of resulting proof before it is published in its final form.

Correspondence concerning this article should be addressed to Christian Blötner, Department of Psychology, TU Dortmund University, Emil-Figge-Str. 50, 44227 Dortmund, Germany. E-Mail: christian.bloetner@tu-dortmund.de 


\begin{abstract}
This meta-analysis investigated how the antagonistic personality trait Machiavellianism (Mach) relates to cognitive and affective empathy. Due to the role of manipulation in Mach, previous research argued that Mach should go along with higher empathic ability but found negative effects very consistently. Thus, some scholars argued that individuals with high scores in Mach had empathic deficits. The current meta-analysis (70 studies, 76 samples, and 232 effect sizes) challenged both perspectives by investigating bivariate and multivariate relations between Mach, self-reported cognitive empathy, cognitive empathic skills, and affective empathy. Further, we tested if gender distributions, student samples, and different utilized Mach scales accounted for differences across studies (i.e., moderated those). Bivariate analyses revealed inverse correlations of Mach with all facets of empathy ( $\rho$ s from -.10 to -.36). The relations with self-reported and performance-based cognitive empathy almost dissolved when controlling for affective empathy. Neither of the proposed moderators significantly explained differences across studies. In general, studies with a high percentage of men and those comprising non-students revealed more diverse correlations than studies with a large proportion of women and studies that exclusively recruited students. The results suggest low affective empathy in Mach but contradict both the empathic deficits- and the "skilled mind reader"-perspectives.

Keywords: Machiavellianism, empathy, mind-reading, meta-analysis
\end{abstract}




\section{Malicious Mind Readers? A Meta-Analysis on Machiavellianism and Cognitive and}

\section{Affective Empathy}

Empathy refers to the recognition or vicarious experience of others' emotional states. It is assumed to inhibit exploitative, socially aversive acts and to facilitate prosocial behavior (Cohen \& Strayer, 1996; Jolliffe \& Farrington, 2004). Some researchers investigated if and under which circumstances perspective taking and predicting others' mental states can be misused, for example in the context of cheating, manipulation, or interpersonal exploitation (e.g., Austin et al., 2007; Bacon \& Regan, 2016; Barlow et al., 2010). A personality trait with a special emphasis on these domains is Machiavellianism (Mach; Christie \& Geis, 1970). Individuals high in Mach find it useful to manipulate; they are exploitative and emotionally detached in interpersonal situations, and have a cynical worldview (Christie \& Geis, 1970; Dahling et al., 2009). In conjunction with subclinical forms of narcissism and psychopathy, Mach forms the Dark Triad. Recently, sadism was added so that the Triad became a Tetrad (e.g., Pajevic et al., 2018). All these traits reveal negative links with agreeableness and positive links with manipulation. However, the manipulative acts differ highly Machiavellian, narcissistic, and psychopathic persons, respectively (Jones, 2017; Paulhus \& Williams, 2002). Highly psychopathic persons rather manipulate others via threat or force but lack a long-term perspective (Jones, 2017; Turner et al., 2019) and narcissists are overtly assertive and self-promotional (Back et al., 2013) without using hidden control mechanisms. These forms of narcissistic and psychopathic controlling of others have nothing to do with the abuse of empathy in the sort of manipulation that expectedly appears in Mach. Moreover, previous research addressed how and why narcissism and psychopathy relate to empathy but only little is known about differentiated associations between Mach and empathy. The present study seeks to address this research gap by combining theoretical reasoning with previous evidence. 


\section{The Roles of Empathy and Related Constructs in Machiavellianism}

Mach is frequently associated with "mind-reading” because Mach refers to manipulative and exploitative intentions for one's selfish ends (Christie \& Geis, 1970). Therefore, various researchers argued that individuals with high scores in Mach had certain social and cognitive skills and traits, such as empathy, Theory of Mind (ToM), and emotional intelligence (EI; Ali et al., 2009; Austin et al., 2007; Jones \& Paulhus, 2009; Paal \& Bereczkei, 2007).

A core differentiation in empathy refers to cognitive and affective empathy (CE and $\mathrm{AE}$, respectively). $\mathrm{CE}$ is the tendency to recognize, infer and understand what others think, feel or intend to do. As opposed to CE, individuals high in AE care for others' feelings, vicariously feel what others feel, or perceive at least a closely related emotion (e.g., feeling pity for others' grief; Jolliffe \& Farrington, 2004, 2006).

ToM refers to ascribing mental states to others, comprehending that individual behavior is due to cognitions and emotions, and taking the perspective of others (e.g., Bensalah et al., 2016; Qualter et al., 2011; Wimmer \& Perner, 1983). It thus reveals substantial overlaps with selfreported and performance-based components of CE (SRCE and PCE, respectively) and numerous scholars have used the labels ToM and CE synonymously (e.g., Ali \& Chamorro-Premuzic, 2010; Barlow et al., 2020; Carpenter et al., 2016; Murphy \& Lilienfeld, 2019; Paal \& Bereczkei, 2007; Pátkai \& Bereczkei, 2016; Stellwagen \& Kerig, 2013; Urbonaviciute \& Hepper, 2020; Vonk et al., 2015). However, research recently failed to find a link between Mach and an individual's ToM (Kerig \& Stellwagen, 2013; Paal \& Bereczkei, 2007). Likewise, a meta-analysis revealed that self-reported empathy and empathic skills do not necessarily converge as self-reported empathy refers to the motivation rather than the actual skill to empathize (Murphy \& Lilienfeld, 2019). Thus, we included studies mentioning Mach and ToM in our meta-analysis and coded the corresponding effect sizes in favor of SRCE or PCE, depending on whether the employed 
instruments reflect self-reported or skill-related concepts of ToM.

EI deals with both cognitive and affective processes and their interaction. It involves intra- and interpersonal abilities and traits, such as self-awareness, emotion regulation, problem solving, empathy, interpersonal relationships, stress management, and general mood (Bar-On, 1997; Petrides et al., 2004; Salovey \& Meyer, 1994; Schutte et al., 2001). Hence, EI includes CE and AE but goes beyond those (Barlow et al., 2010; Moriarty et al., 2001). Miao et al.'s (2019) meta-analysis revealed negative links between Mach and both trait and ability EI. However, the effect sizes reported in their meta-analysis mingle interpersonal and intrapersonal, as well as cognitive and affective components of EI. The analysis has thus limited explanatory power regarding potentially distinct cognitive and affective processes and actual interpersonal skills in Mach and it remains unclear whether the findings on ability EI reflect low intrapersonal skills in Mach or if they indicate low interpersonal skills. However, as EI involves empathy-related phenomena, our meta-analysis also considered studies that reported correlations between Mach and particular facets of EI. We coded the empirical effect sizes depending on whether the reported facets referred to cognitive or affective aspects of EI.

As CE refers to recognizing emotions and thoughts without necessarily sharing those, the stereotype of the skilled and malicious Machiavellian mind reader implies higher CE than AE (see also Pursoo, 2013) so that it is worthwhile to distinguish between CE and AE when discussing the role of empathy in Mach. However, a variety of studies assessed empathy (or related constructs) via self-report scales and mingled $\mathrm{CE}$ and $\mathrm{AE}$ in an overall score. Given consistent negative correlations between Mach and (overall) empathy, recent research concluded empathic deficits in Mach (e.g., Ali et al., 2009; Ali \& Chamorro-Premuzic, 2010; Heym et al., 2019; Jonason \& Krause, 2013). This conclusion is problematic for three intertwined reasons. First, self-reported empathy is almost unrelated to actual empathic skills (Murphy \& Lilienfeld, 
2019) as typically assessed by identifying emotional expressions in pictures of the eye region or the entire face (Costanzo \& Archer, 1989; Matsumoto \& Ekman, 1989; Nowicki \& Duke, 1994). Second, SRCE and AE overlap considerably both conceptually and empirically (e.g., Giammarco \& Vernon, 2014; Murphy et al., 2020; Murphy \& Lilienfeld, 2019; Turner et al., 2019; Vachon \& Lynam, 2016; see especially Jolliffe \& Farrington, 2006, on the confusion of SRCE and AE in some scales), but studies have seldom controlled for the overlap. Third, it appears to be questionable if negative correlations between Mach and empathy constructs actually indicate a lack of empathic skills: Given the motivational expression of self-report empathy scales, low correlations between Mach and AE, in particular, align with typical elements of Mach, such as disregard of others (Christie \& Geis, 1970) and indifference in social issues (Jones \& Paulhus, 2011). Consistent with this, Murphy et al. (2020) found that Mach correlated positively with affective dissonance (i.e., feeling good when others feel bad) and negatively with affective resonance (i.e., feeling good when others feel good). Likewise, in analyses by Ali and colleagues (Ali et al., 2009; Ali \& Chamorro-Premuzic, 2010), those high in Mach reported differential emotional intensities in affective states when confronted with stimuli that provided different emotional valences. These findings suggest that highly Machiavellian individuals must have at least a minimum capacity to recognize and discriminate mental information in others, but none of the evidence gives rise to the assumption of diminished empathic skills.

Just as SRCE and PCE do not converge (Murphy \& Lilienfeld, 2019), the will to employ cognitive or emotional manipulation in Mach does not necessarily equal the actual ability. In the same vein, the theory of Mach does not postulate manipulative or exploitative skills but a belief in the utility of manipulation and exploitation or the endorsement of attitudes favoring those (Austin et al., 2007; Christie \& Geis, 1970; Jones \& Paulhus, 2009). It is thus more likely that a particular person's advantages or disadvantages in manipulation and empathic skills are due to 
the interaction between Mach and other characteristics (i.e., moderators). Jones and Paulhus (2011) acknowledged that individuals high in Mach were actually able to reason morally and to consider others' perspectives, but they do not care ("high indifference"; see also Austin et al., 2007). Due to both high antagonism and disregard of others related to low AE and manipulative attempts, we suggested low $\mathrm{AE}$ in Mach rather than $\mathrm{CE}$. CE on the contrary is a means to gather social information (Bacon \& Regan, 2016; Barnett \& Thompson, 1985; Pursoo, 2013; Wai \& Tiliopoulos, 2012) but the skill or motivation to see the world from another person's point of view (i.e., CE) does not necessarily equal the motivation to care for this person (i.e., AE; Batanova \& Loukas, 2011, cited in Pursoo, 2013). Combining the above reasoning and evidence with considerable overlaps between AE and SRCE, we hypothesized that Mach reveals negative correlations with SRCE and AE and a null relation with PCE. Moreover, we expected that controlling for overlaps yields null relations between Mach and both PCE and SRCE and a negative link between Mach and AE. To account for variability across studies, we further sought to inspect moderators.

\section{Moderators of the Relations between Machiavellianism and Empathy}

\section{Gender Effects}

A common observation is that many studies have an overwhelming proportion of females. As men consistently score higher on Mach and lower on empathy than women (e.g., Jolliffe \& Farrington, 2006; Jonason et al., 2013), empirical correlations might differ between the sexes. Thus, we expected that the relations between Mach and empathy found in predominantly female samples differed from the relations found in predominantly male samples (proportion of females $>50$ percent and $<50$ percent, respectively).

\section{Student Samples vs. Broad Population}

Besides unbalanced gender distributions, many studies rely on student samples and 
generalize their results to a much broader population. Meta-analyses found a positive link of empathy with education and a null link with Mach (Jolliffe \& Farrington, 2006; O’Boyle et al., 2013). Accordingly, study results on Mach-empathy relations from student samples might not be generalizable to non-students. We tested this as an open research question.

\section{Assessment of Machiavellianism}

As recommended by a reviewer, we tested whether different operationalizations of Mach

(i.e., Mach scales) account for different correlations between Mach and the facets of empathy. We did not make any expectations regarding specific scales.

\section{Method}

\section{Literature Screening}

Literature screening took place on PsycInfo, PubMed, and PsycArticles. We used the search term "Machiavelli* OR mach OR Dark AND (tetrad OR triad) AND (empath* OR perspective OR feeling* OR emotion* OR mind)". Since Christie and Geis' (1970) seminal work initiated the research on Mach, we searched for studies from 1970 to 2021. Additionally, we screened the references of included studies for eligible articles and included articles that we received from authors we contacted for further information. We considered quantitative studies in English or German that mentioned Mach and at least one empathy facet (PCE, SRCE, or AE). We excluded studies that relied on mixed or unclear empathy measures (i.e., unidimensional empathy measures), as well as studies that referred to the modification of others' emotions, altruism, ethical/moral aspects, identification with others, and prosocial motivations and behaviors. Besides genuine empathy, EI, and ToM scales, we regarded variables that refer to central characteristics of $\mathrm{AE}$ and $\mathrm{CE}$, for example, if a measure assessed the ascription, recognition, or co-experience of emotions. We considered product-moment correlations and excluded rank correlations, point-biserial correlations, and beta coefficients from multiple 
regression. Figure 1 presents a PRISM chart addressing the procedure of inclusion or exclusion of studies (Moher et al., 2009). The supplement provides the dataset, the R script, as well as forest and funnel plots (https://osf.io/qszb4/?view_only=9c815647f3b444aeaaa8602e69f2d457).

\section{Figure 1}

PRISM Chart to Illustrate the Flow of Inclusion and Exclusion of Studies

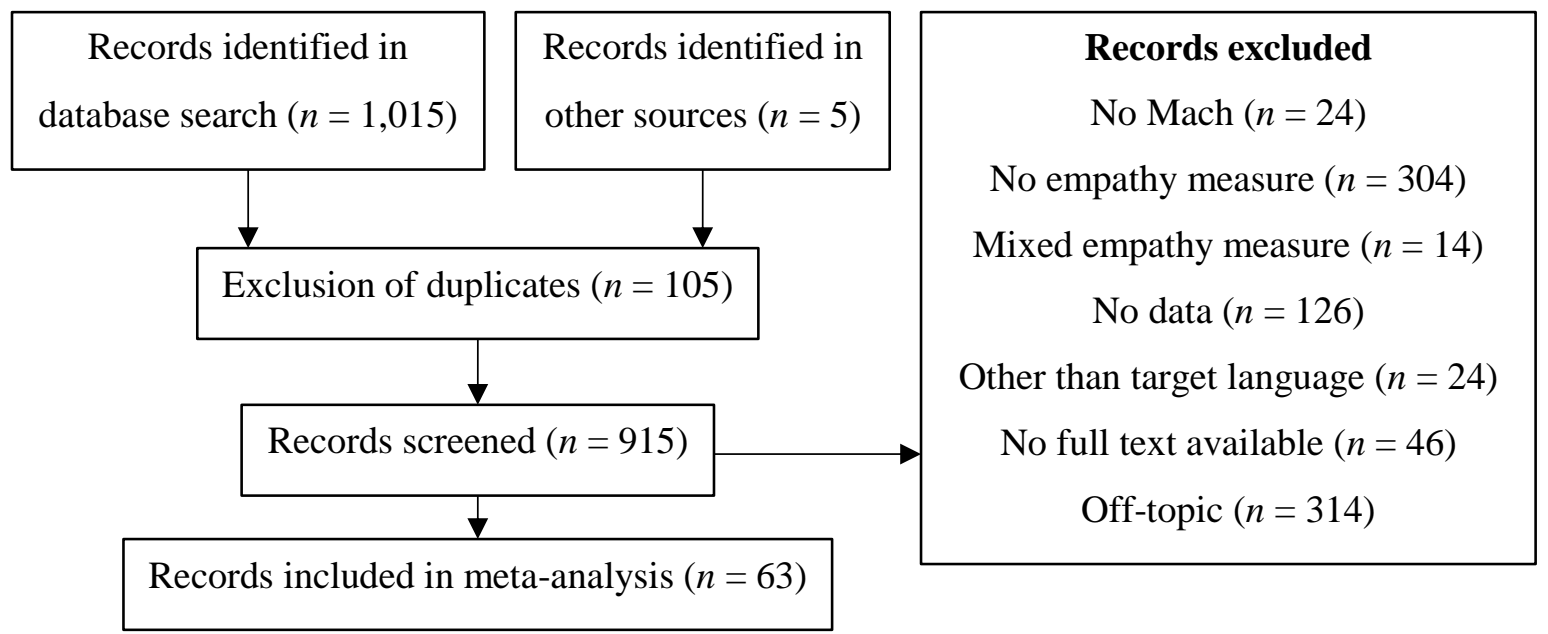

Note. The category no data contains non-empirical papers, qualitative reviews, or studies without accessible data.

\section{Literature Coding}

If a publication reported a compound empathy score of genuinely distinctive $\mathrm{CE}$ and $\mathrm{AE}$ subscales, we contacted the corresponding author and asked for the differential correlations. We derived the assignment of existing empathy measures to SRCE, PCE, and AE from Jolliffe and Farrington (2004), Murphy and Lilienfeld (2019), and Vachon et al. (2014). If a primary study used more than one empathy measure, we averaged the correlations across each domain. To examine whether different Mach scales yield differential relations with empathy, besides computing overall effect sizes, we carried out the analyses at the Mach scale level. If a study used more than one Mach measure or different subscales from a Mach scale, we mentioned the correlations for each scale or subscale in separated rows. To account for dependencies among correlations between a facet of empathy and different Mach scales reported in a study, the 
employed meta-analysis software (R package psychmeta version 2.4.2; Dahlke \& Wiernik, 2019) averaged the correlations per study (e.g., correlations between different Mach scales and SRCE). As some studies reported more than one Mach scale, the number of included studies for the overall effect sizes is smaller than the sum of the included studies mentioning different Mach scales. If a study re-analyzed data from another study, we included the information from the original study. Two coders (master-level psychologists) carried out all codings independently, discussed their codings, and, in case of disagreement, reached a consensus.

\section{Statistical Analyses}

If a study did not report an estimation of reliability, we replaced the value with the mean of the observed values for the respective scale. To account for heterogeneity across studies and for expected differential correlational patterns (students vs. non-students; gender-specific relations between Mach and empathy), we conducted random-effects analyses (restricted maximum likelihood method).

\section{Results}

\section{Overall Correlations and Meta-Regression}

The included records contained 70 studies, examined 76 samples, and included 232 effect sizes. Mach yielded negative correlations with all facets of empathy (SRCE: $\rho=-.24,95 \%$ CI [$.29,-.18]$, PCE: $\rho=-.10,95 \%$ CI $[-.17,-.03]$ AE: $\rho=-.36,95 \%$ CI $[-.41,-.30])$. SRCE and AE were positively related to each other $(\rho=.52,95 \% \mathrm{CI}=[.46, .59])$, but both unrelated to PCE (SRCE: $\rho=.12,95 \% \mathrm{CI}=[-.06, .30]$; $\mathrm{AE}: \rho=.14,95 \% \mathrm{CI}=[-.03, .31])$. The meta-regression of Mach on SRCE, PCE, and AE revealed uniformly negative effects (in this order), $\beta=-.07,95 \%$ CI $[-.11,-.02], \beta=-.05,95 \%$ CI $[-.09,-.01]$, and $\beta=-.31,95 \%$ CI $[-.36,-.26]$.

\section{Moderations of the Observed Correlations}

As expected, the overall correlations revealed moderate to large heterogeneity across 
studies, $Q \mathrm{~s}(21$ to 59$)$ from 48.45 to 723.39 , all $p \mathrm{~s} \leq .01, I^{2} \mathrm{~s}$ from .59 to .90 . To test the moderator hypotheses, we carried out subgroup analyses for student samples (only students), non-student samples (only non-students), high female samples, and low female samples (cutoff = 50\%). As indicated by overlapping $95 \%$ CIs, there were no differences between the respective subgroups (see Table 1). The Mach scales from the Dirty Dozen Scale (DD; Jonason \& Webster, 2010) and the Short Dark Triad Scale (SD3; Jones \& Paulhus, 2014), as well as the Mach-IV, Mach-V, and “other” scales (in this case Mach-III; all by Christie \& Geis, 1970) yielded negative correlations with SRCE. Conversely, the Kiddie Mach Scale (the children version of the Mach-IV; Christie \& Geis, 1970) and the Machiavellian Personality Scale (MPS; Dahling et al., 2009) were unrelated to SRCE, as indicated by $95 \%$ CIs excluding zero. DD-Mach and the Mach-IV yielded negative correlations with PCE, whereas the 95\% CIs of the remaining Mach scales included zero. All Mach scales revealed negative correlations with AE, except for the Kiddie Mach Scale for which the $95 \%$ CI overlapped with zero (see Table 1).

\section{Table 1}

Meta-Analytical Correlations between Machiavellianism and Empathy

\begin{tabular}{lccccccc}
\hline \multicolumn{1}{c}{ Facet / subgroup } & $I^{2}$ & $k$ & $N$ & $r$ & $\rho$ & $80 \% \mathrm{CV}$ & $95 \% \mathrm{CI}$ \\
\hline SRCE & 90 & 51 & 18,434 & -.18 & -.24 & {$[-.47, .003]$} & {$[-.29,-.18]$} \\
By Sample & & & & & & & \\
$\quad$ Students & 79 & 18 & 5,054 & -.19 & -.25 & {$[-.43,-.07]$} & {$[-.33,-.17]$} \\
$\quad$ Non-Students & 97 & 6 & 3,702 & -.06 & -.09 & {$[-.56, .39]$} & {$[-.43, .25]$} \\
By Sex & & & & & & & \\
$\quad$ High-Female & 78 & 35 & 10,635 & -.21 & -.26 & {$[-.43,-.09]$} & {$[-.31,-.21]$} \\
$\quad$ Low-Female & 97 & 10 & 6,578 & -.12 & -.16 & {$[-.57, .25]$} & {$[-.38, .06]$} \\
By Mach Scale & & & & & & & \\
$\quad$ DD-Mach & 84 & 13 & 5,427 & -.19 & -.23 & {$[-.41,-.04]$} & {$[-.32,-.14]$} \\
Kiddie Mach & 99 & 3 & 2,163 & -.02 & -.06 & {$[-1.00, .89] \dagger$} & {$[-1.00,1.00] \dagger$} \\
Mach-IV & 87 & 22 & 7,234 & -.20 & -.26 & {$[-.49,-.04]$} & {$[-.35,-.17]$} \\
$\quad$ Mach-V & - & 1 & 576 & -.16 & -.20 & - & {$[-.31,-.10]$}
\end{tabular}




$\begin{array}{lccccccc}\text { MPS } & 91 & 3 & 1,364 & -.21 & -.24 & {[-.65, .16]} & {[-.81, .33]} \\ \text { SD3-Mach } & 79 & 14 & 4,470 & -.18 & -.23 & {[-.39,-.07]} & {[-.31,-.15]} \\ \text { other } & - & 1 & 107 & -.38 & -.48 & - & {[-.69,-.28]} \\ \text { PCE } & 59 & 22 & 4,907 & -.08 & -.10 & {[-.26, .06]} & {[-.17,-.03]} \\ \text { By Sample } & & & & & & & \\ \quad \text { Students } & 57 & 9 & 2,168 & -.11 & -.14 & {[-.28,-.001]} & {[-.25,-.03]} \\ \text { Non-Students } & 38 & 5 & 335 & -.14 & -.18 & {[-.40, .04]} & {[-.44, .08]} \\ \text { By Sex } & & & & & & & \\ \quad \text { High-Female } & 68 & 17 & 4,563 & -.08 & -.11 & {[-.29, .07]} & {[-.20,-.02]} \\ \text { Low-Female } & 2 & 4 & 264 & -.01 & -.02 & {[-.02,-.02]} & {[-.25, .22]} \\ \text { By Mach Scale } & & & & & & & {[-.02} \\ \text { DD-Mach } & - & 1 & 799 & -.09 & -.13 & - & {[-.23,-.03]} \\ \text { Kiddie Mach } & 59 & 3 & 189 & -.22 & -.28 & {[-.65, .09]} & {[-.91, .35]} \\ \text { Mach-IV } & 57 & 8 & 1,819 & -.11 & -.14 & {[-.31, .02]} & {[-.28,-.01]} \\ \text { Mach-V } & 47 & 3 & 656 & -.11 & -.14 & {[-.37, .09]} & {[-.60, .32]} \\ \text { SD3-Mach } & 51 & 4 & 837 & .02 & .02 & {[-.12, .17]} & {[-.17, .22]} \\ \text { other } & 33 & 4 & 780 & 0 & 0 & {[-.11, .10]} & {[-.19, .19]} \\ \text { AE } & 91 & 60 & 20,424 & -.27 & -.36 & {[-.62,-.09]} & {[-.41,-.30]}\end{array}$

By Sample

Students

Non-Students

$82 \quad 22$

5,730

$-.30$

$-.39$

$[-.61,-.18]$

$[-.48,-.31]$

By Sex

High-Female

$85 \quad 40$

4,941

$\begin{array}{lll}-.13 & -.19 \quad[-.62, .24]\end{array}$

$[-.42, .04]$

Low-Female

$97 \quad 11$

11,611

$-.29$

$-.38$

$[-.60,-.16]$

$[-.44,-.32]$

By Mach Scale

DD-Mach

89

Kiddie Mach

$89 \quad 13$

5,427

$-.24$

$[-.67, .17]$

$[-.46,-.04]$

Mach-IV

Mach-V

MPS

SD3-Mach

other

$98 \quad 5$

2,723

$-.11 \quad-.18$

$[-.53,-.08]$

$[-.41,-.19]$

$85 \quad 26$

- 1

7,672

$-.29$

$-.39$

$[-.85, .50]$

$[-.73, .38]$

$\begin{array}{lll}576 & -.27 & -.34\end{array}$

$[-.62,-.16]$

$[-.47,-.30]$

$73 \quad 3$

1,36

$\begin{array}{ll}-.37 & -.44\end{array}$

[-.64, -.24]

$[-.44,-.25]$

$87 \quad 15$

4,783

$-.31 \quad-.40$

$[-.62,-.17]$

$[-.75,-.13]$

$71 \quad 3$

786

$-.35 \quad-.45$

$[-.70,-.20]$

$[-.50,-.30]$

Note. $I^{2}=$ Percentage of variance accounted for by true heterogeneity between studies. $k=$ Number of included studies. $N=$ Total sample size. $r=$ Weighted average correlation. $\rho=$ Weighted average correlation, corrected for 
unreliability. $80 \% \mathrm{CV}=80 \%$ credibility interval. $95 \% \mathrm{CI}=95 \%$ confidence interval. ${ }^{\dagger}$ Values outside the $\mathrm{CI}$ or CV $[-1,+1]$ were corrected.

\section{Discussion}

The current meta-analysis aimed at clarifying the relations between the antagonistic personality trait Machiavellianism on one hand and SRCE, PCE, and AE on the other. We hypothesized a bivariate null correlation between Mach and PCE as well as negative bivariate correlations between Mach and both SRCE and AE. We used meta-regression to test if PCE and SRCE still relate to Mach when controlling for AE. To address the heterogeneity across the samples, we tested if the correlations differed between student and non-student samples, between samples with a high and a low percentage of women, and between different Mach scales, respectively.

For the evaluation of the meta-analytical effect sizes, we referred to Gignac and Szodorai (2016) and Funder and Ozer (2019) who deemed correlations as very small, small, moderate, large, and very large when exceeding $r \mathrm{~s}=|.05|,|.10| ,.20|| .30 \mid$, , and |.40|, respectively. As expected, the bivariate overall analyses revealed negative correlations between Mach and all facets of empathy. However, both in bivariate and multivariate analyses, PCE explained only about one percent of the variance of Mach. SRCE revealed a moderate-to-strong negative correlation with Mach but also showed very large intersections with AE. Accordingly, SRCE only had a very small relation with Mach when controlling for AE. AE, on the contrary, had a very strong relation with Mach both in bivariate analyses and in meta-regression.

Neither the percentage of females, the sample type (students vs. non-students), nor the measures of Mach emerged as moderators. For each correlation of Mach with a facet of empathy, the respective confidence intervals of non-student samples entirely included the confidence intervals of student samples and the confidence intervals of low-female samples entirely included 
the confidence intervals of high-female samples. Additionally, the confidence intervals for lowfemale and non-student samples included zero (except for the interval of low-female samples in the relation between Mach and AE), whereas those for high-female- and student-samples did not.

\section{Differential Correlations as a Function of the Theoretical Perspective on Mach}

A major point regards the issue that most studies treated Mach as unidimensional, although there is evidence on the superiority of the multidimensional assessment of Mach (e.g., Andreou, 2004; Andrew et al., 2008; Dahling et al., 2009; Hart et al., 2020; Monaghan et al., 2016, 2018, 2020; Sutton \& Keogh, 2001). The research is also aware of the strengths and weaknesses of diverse Mach scales concerning the factor structure and validity (Dahling et al., 2009; Paulhus \& Jones, 2015). Some scholars suggested that different facets of Mach might account for differential or in some cases even opposing effects on empathy (Al Aïn et al., 2013; Hart et al., 2020). Our results support this assumption in that some Mach scales revealed more negative correlations than others did and that some measures even revealed null correlations. Nevertheless, there remained a large proportion of variance unaccounted for by the Mach scale used. According to Hart et al. (2020), long-term oriented, agentic aspects of Mach account for advantages in PCE, whereas disadvantages in PCE are due to distrustful, misanthropic facets of Mach. In the current meta-analysis, often-employed alternatives to the Mach-IV were short scales that mix up distinguishable facets of their higher-order construct and thus blur distinct relations between Mach and crucial criteria. However, from the coded studies, only about a handful considered the multifaceted nature of Mach by reporting separated correlations per dimension.

\section{Motivation vs. Skill to Empathize}

Carpenter et al. (2016) noted that being successful at recognizing others' feelings requires both motivation and actual skills. Kajonius and Björkman (2020) found that Mach has almost no effect on empathic ability but a strongly negative one on empathic dispositions. Similarly, many 
empathy scales might suffer from contamination of empathy with sympathy (Jolliffe \& Farrington, 2006). In line with highly Machiavellian individuals' disregard of others and low interpersonal warmth (Christie \& Geis, 1970; Dahling et al., 2009; Wastell \& Booth, 2003), the negative, meta-analytically observed correlation between Mach and AE should thus indicate low motivation or low interest in others' cognitive and affective processes rather than a low capacity to show empathic behavior. Consistent with this, Murphy and Lilienfeld (2019) pointed out that neither SRCE nor AE serve as valid indicators of actual empathic skills and according to Kajonius and Björkman (2020, p. 4), "ability and traits are very different empathy-constructs".

\section{Moderating Variables}

The confidence intervals of low- and high-female samples overlapped for all correlations between Mach and empathy, but only the respective confidence intervals for low-female samples contained zero. In general, the effects in predominantly male samples were much more heterogeneous than the effects in predominantly female samples. However, the question remains whether women are more empathic than men are or if women - due to social role expectationsonly perceive themselves as being more empathic (Jolliffe \& Farrington, 2006). The results for students and non-students revealed a similar picture. Note that the category of "non-students" is not very exclusive because those who never studied, those who completed or dropped out of their studies, and those who are not yet enrolled (children, adolescents) were in the same category. Likewise, the category "students" might not be an adequate indicator of high intelligence or high education. However, there were only relatively few studies on non-students and the total sample size was comparatively low. Nevertheless, the moderator analysis emphasized that it is not advantageous to generalize from high female or student-only samples to the entire population as our analyses strongly suggested that there must be other moderators. For instance, Heym et al. (2021) found that about a fifth of their sample had high scores on both empathy and antagonistic 
personality traits. Findings like these give rise to the idea that a Machiavellian "evil genius" is possible - given further individual characteristics. To explain Machiavellian manipulative success, future research might be interested in the examination of the interaction between Mach and PCE. Thereby, individuals with high scores in both Mach and PCE should be better able to manipulate others for their egoistic goals. To disentangle empathic motivation and empathic skills, future research could also test if specific situational stimuli alter the motivation to empathize in individuals high in Mach (e.g., via potential gain of resources).

\section{Limitations}

Besides the correlational nature (i.e., limited causal interpretability), the proneness of selfreport scales toward social desirable responding, and the lacking ecological validity of static images for the assessment of PCE (e.g., Ali \& Chamorro-Premuzic, 2010; Pajevic et al., 2018; Puthillam et al., 2019; Wai \& Tiliopoulos, 2012), the current study's moderator analyses should be interpreted with caution. A rule of thumb says that meta-analytical categorical moderator analyses require at least ten samples per group to gather reliable results (Kirca et al., 2012). The subgroup analyses considered only very few studies for the low-female groups, non-student groups as well as some Mach scales (e.g., Mach-V, Kiddie Mach, and MPS) and several combinations could not attain the rule of thumb of at least ten groups. This was especially critical for PCE because there were only a few studies assessing PCE in non-student and low-female groups. Furthermore, the total sample sizes of studies examining PCE were very small (see Table 1). Nevertheless, the current study has pointed out that the generalization of female- or studentsamples to the broad population is limited. However, a general point refers to the fact that in many of the included studies, the assessments of empathy and Mach were only byproducts of more general objectives of the particular examination (e.g., construct validation). This being said, this also suggests that the effect sizes are not very susceptible to publication bias (see also 
Murphy \& Lilienfeld, 2019). The last limitation we would like to state is that some of the primary studies have purposefully recruited from very diverse populations (e.g., imprisoned men and women, graduates in certain vocational areas, children, and patients in clinical settings). Due to the low number of studies with these special samples, we could not test this dependence reliably. Therefore, future research is needed.

\section{Conclusions}

Earlier research has stated that those with high Mach scores were unable to recognize what others think or unable to feel what others feel (e.g., Ali et al., 2009; Ali \& ChamorroPremuzic, 2010; Heym et al., 2019; Puthillam et al., 2019). At the same time, a stream of research claimed the dark side of empathy (e.g., Andrew et al., 2008; Austin et al., 2007; Barlow et al., 2010; Barnett \& Thompson, 1985; Heym et al., 2021; Kajonius \& Björkman, 2020; Nagler et al., 2014). Given the very small effects for PCE, the strong overlaps between SRCE and AE, and the heterogeneity of observed correlations, there is little evidence suggesting empathic advantages or disadvantages for individuals with high Mach scores per se. Thus, assuming either "mind reading skills" or "empathic deficits" for highly Machiavellian individuals appears to be deprecated. Given the very large percentage of the shared variance between AE and SRCE, it remains questionable whether current empathy scales can discriminate between deliberate identification of mental states in others (i.e., SRCE) and the immediate, automatic co-experience of emotions at all (i.e., AE; see also Giammarco \& Vernon, 2014; Jolliffe \& Farrington, 2006; Schimmenti et al., 2019). For example, in Giammarco and Vernon's (2014) study, the mediating effect of SRCE between dark traits and forgivingness dissolved when the authors added AE as another parallel mediator (see also Turner et al., 2019, for a similar finding). From an evolutionary point of view, it is adaptive to aim for individual goals without considering consequences for others (Jonason \& Krause, 2013; Jonason \& Kroll, 2015; Wai \& Tiliopoulos, 
2012; Wastell \& Booth, 2003). Hence, as Mach is supposed to be a normal trait with a normal distribution in the general population (Paulhus \& Williams, 2002), a lack of empathy perspective is largely inappropriate.

\section{Acknowledgments}

This research did not receive any specific grant from funding agencies in the public, commercial, or not-for-profit sectors.

Declarations of interest: none 


\section{References}

References marked with an asterisk indicate studies that were included in the meta-analysis.

* Al Aïn, S., Carré, A., Fantini-Hauwel, C., Baudouin, J.-Y., \& Besche-Richard, C. (2013). What is the emotional core of the multidimensional Machiavellian personality trait? Frontiers in Psychology, 4. https://doi.org/10.3389/fpsyg.2013.00454

* Ali, F., Amorim, I. S., \& Chamorro-Premuzic, T. (2009). Empathy deficits and trait emotional intelligence in psychopathy and Machiavellianism. Personality and Individual Differences, 47(7), 758-762. https://doi.org/10.1016/j.paid.2009.06.016

* Ali, F., \& Chamorro-Premuzic, T. (2010). Investigating theory of mind deficits in nonclinical psychopathy and Machiavellianism. Personality and Individual Differences, 49(3), 169174. https://doi.org/10.1016/j.paid.2010.03.027

* Amelang, M., \& Steinmayr, R. (2006). Is there a validity increment for tests of emotional intelligence in explaining the variance of performance criteria? Intelligence, 34(5), 459468. https://doi.org/10.1016/j.intell.2006.03.003

Andreou, E. (2004). Bully/victim problems and their association with Machiavellianism and selfefficacy in Greek primary school children. British Journal of Educational Psychology, 74(2), 297-309. https://doi.org/10.1348/000709904773839897

* Andrew, J., Cooke, M., \& Muncer, S. J. (2008). The relationship between empathy and Machiavellianism: An alternative to empathizing-systemizing theory. Personality and Individual Differences, 44(5), 1203-1211. https://doi.org/10.1016/j.paid.2007.11.014

* Arefi, M. (2012). The relation between relational/overt aggression and prosocial behavior with Machiavellianism and empathy in Iranian primary school. Global Journal of Guidance and Counselling, 2(2).

Austin, E. J., Farrelly, D., Black, C., \& Moore, H. (2007). Emotional intelligence, 
Machiavellianism and emotional manipulation: Does EI have a dark side? Personality and Individual Differences, 43(1), 179-189. https://doi.org/10.1016/j.paid.2006.11.019

Bar-On, R. (1997). Development of the Bar-On EQ-i: A measure of emotional intelligence and social intelligence. Multi-Health Systems.

* Barlow, A., Qualter, P., \& Stylianou, M. (2010). Relationships between Machiavellianism, emotional intelligence and theory of mind in children. Personality and Individual Differences, 48(1), 78-82. https://doi.org/10.1016/j.paid.2009.08.021

Back, M. D., Küfner, A. C. P., Dufner, M., Gerlach, T. M., Rauthmann, J. F., \& Denissen, J. J. A. (2013). Narcissistic admiration and rivalry: Disentangling the bright and dark sides of narcissism. Journal of Personality and Social Psychology, 105(6), 1013-1037. https://doi.org/10.1037/a0034431

Bacon, A. M., \& Regan, L. (2016). Manipulative relational behaviour and delinquency: Sex differences and links with emotional intelligence. Journal of Forensic Psychiatry \& Psychology, 27(3), 331-348. https://doi.org/10.1080/14789949.2015.1134625

Barnett, M. A., \& Thompson, S. (1985). The role of perspective taking and empathy in children's Machiavellianism, prosocial behavior, and motive for helping. Journal of Genetic Psychology, 146(3), 295-305. https://doi.org/10.1080/00221325.1985.9914459

Bensalah, L., Caillies, S., \& Anduze, M. (2016). Links among cognitive empathy, theory of mind, and affective perspective taking by young children. Journal of Genetic Psychology: Research and Theory on Human Development, 177(1), 17-31. https://doi.org/10.1080/00221325.2015.1106438

* Berger, C., Batanova, M., \& Cance, J. D. (2015). Aggressive and prosocial? Examining latent profiles of behavior, social status, Machiavellianism, and empathy. Journal of Youth and Adolescence, 44(12), 2230-2244. https://doi.org/10.1007/s10964-015-0298-9 
* Bloxsom, C. A. J., Firth, J., Kibowski, F., Egan, V., Sumich, A. L., \& Heym, N. (2021). Dark shadow of the self: How the Dark Triad and empathy impact parental and intimate adult attachment relationships in women. Forensic Science International: Mind and Law, 2, 100045. https://doi.org/10.1016/j.fsiml.2021.100045

* Bryant, W. P. (1977). Machiavellianism, perspective taking, and partner's response as predictors of interpersonal behavior measured by a modified Prisoner's Dilemma game [Doctoral dissertation, Loyola University Chicago]. eCommons. https://ecommons.luc.edu/luc_diss/1577/

* Cantarero, K., van Tilburg, W. A. P., \& Szarota, P. (2018). Differentiating everyday lies: A typology of lies based on beneficiary and motivation. Personality and Individual Differences, 134, 252-260. https://doi.org/10.1016/j.paid.2018.05.013

* Carnahan, T., \& McFarland, S. (2007). Revisiting the Stanford Prison Experiment: Could participant self-selection have led to the cruelty? Personality and Social Psychology Bulletin, 33(5), 603-614. https://doi.org/10.1177/0146167206292689

Carpenter, J. M., Green, M. C., \& Vacharkulksemsuk, T. (2016). Beyond perspective-taking: Mind-reading motivation. Motivation and Emotion, 40, 358-374. http://dx.doi.org/10.1007/s11031-016-9544-z

Christie, R., \& Geis, F. L. (1970). Studies in Machiavellianism. Academic Press.

Cohen, D., \& Strayer, J. (1996). Empathy in conduct-disordered and comparison youth. Developmental Psychology, 32(6), 988-998. https://doi.org/10.1037/0012-1649.32.6.988

* Cohen, T. R., Panter, A. T., Turan, N., Morse, L., \& Kim, Y. (2014). Moral character in the workplace. Journal of Personality and Social Psychology, 107(5), 943-963. https://doi.org/10.1037/a0037245

* Corte, K. de, Buysse, A., Verhofstadt, L. L., Roeyers, H., Ponnet, K., \& Davis, M. H. (2007). 
Measuring empathic tendencies: Reliability and validity of the Dutch version of the Interpersonal Reactivity Index. Psychologica Belgica, 47(4), 235-260. https://doi.org/10.5334/pb-47-4-235

Costanzo, M., \& Archer, D. (1989). Interpreting the expressive behavior of others: The Interpersonal Perception Task. Journal of Nonverbal Behavior, 13, 225-245. https://doi.org/10.1007/BF00990295

* Czarna, A. Z., Jonason, P. K., Dufner, M., \& Kossowska, M. (2016). The Dirty Dozen Scale: Validation of a Polish version and extension of the nomological net. Frontiers in Psychology, 7, 445. https://doi.org/10.3389/fpsyg.2016.00445

Dahling, J. J., Whitaker, B. G., \& Levy, P. E. (2009). The development and validation of a new Machiavellianism scale. Journal of Management, 35(2), 219-257. https://doi.org/10.1177/0149206308318618

Dahlke, J. A., \& Wiernik, B. M. (2019). psychmeta: An R package for psychometric metaanalysis. Applied Psychological Measurement, 43(5), 415-416. https://doi.org/10.1177/0146621618795933

Funder, D. C., \& Ozer, D. J. (2019). Evaluating effect size in psychological research: Sense and nonsense. Advances in Methods and Practices in Psychological Science, 2(2), 156-168. https://doi.org/10.1177/2515245919847202

* Gamache, D., Savard, C., \& Maheux-Caron, V. (2018). French adaptation of the Short Dark Triad: Psychometric properties and a head-to-head comparison with the Dirty Dozen. Personality and Individual Differences, 122, 164-170. https://doi.org/10.1016/j.paid.2017.10.027

* Geng, Y., Qin, B., Xia, D., \& Ye, Q. (2011). Reliability and validity of the Kiddie Mach Scale in Chinese children. Psychological Reports, 108(1), 229-238. 
https://doi.org/10.2466/03.09.17.pr0.108.1.229-238

* Giammarco, E. A., \& Vernon, P. A. (2014). Vengeance and the Dark Triad: The role of empathy and perspective taking in trait forgivingness. Personality and Individual Differences, 67, 23-29. https://doi.org/10.1016/j.paid.2014.02.010

Gignac, G. E., \& Szodorai, E. T. (2016). Effect size guidelines for individual differences researchers. Personality and Individual Differences, 102, 74-78. https://doi.org/10.1016/j.paid.2016.06.069

* Greenier, K. D. (2018). The relationship between personality and schadenfreude in hypothetical versus live situations. Psychological Reports, 121(3), 445-458. https://doi.org/10.1177/0033294117745562

* Hart, W., Breeden, C. J., \& Kinrade, C. (2020). Re-conceptualizing Machiavellianism and social-cognitive skills: Machiavellianism blends deficient, proficient, and average socialcognitive skills. Journal of Individual Differences. Advance online publication. https://doi.org/10.1027/1614-0001/a000340

* Heym, N., Firth, J., Kibowski, F., Sumich, A., Egan, V., \& Bloxsom, C. A. J. (2019). Empathy at the heart of darkness: Empathy deficits that bind the Dark Triad and those that mediate indirect relational aggression. Frontiers in Psychiatry, 10, 95.

https://doi.org/10.3389/fpsyt.2019.00095

* Heym, N., Kibowski, F., Bloxsom, C. A., Blanchard, A., Harper, A., Wallace, L., Firth, J., \& Sumich, A. (2021). The dark empath: Characterising dark traits in the presence of empathy. Personality and Individual Differences, 169. 110172. https://doi.org/10.1016/j.paid.2020.110172

Jolliffe, D., \& Farrington, D. P. (2004). Empathy and offending: A systematic review and metaanalysis. Aggression and Violent Behavior, 9(5), 441-476. 
https://doi.org/10.1016/j.avb.2003.03.001

Jolliffe, D., \& Farrington, D. P. (2006). Development and validation of the Basic Empathy Scale. Journal of Adolescence, 29(4), 589-611. https://doi.org/10.1016/j.adolescence.2005.08.010

* Jonason, P. K., \& Krause, L. (2013). The emotional deficits associated with the Dark Triad traits: Cognitive empathy, affective empathy, and alexithymia. Personality and Individual Differences, 55(5), 532-537. https://doi.org/10.1016/j.paid.2013.04.027

* Jonason, P. K., \& Kroll, C. H. (2015). A multidimensional view of the relationship between empathy and the Dark Triad. Journal of Individual Differences, 36(3), 150-156. https://doi.org/10.1027/1614-0001/a000166

Jonason, P. K., Lyons, M., Bethell, E. J., \& Ross, R. (2013). Different routes to limited empathy in the sexes: Examining the links between the Dark Triad and empathy. Personality and Individual Differences, 54(5), 572-576. https://doi.org/10.1016/j.paid.2012.11.009

Jonason, P. K., \& Webster, G. D. (2010). The Dirty Dozen: A concise measure of the Dark Triad. Psychological Assessment, 22, 420-432. https://doi.org/10.1037/a0019265

Jones, D. N. (2017). Machiavellianism. In V. Zeigler-Hill, \& T. K. Shackelford (Eds.), Encyclopedia of Personality and Individual Differences (pp. 1-9). Springer. https://doi.org/10.1007/978-3-319-28099-8_1245-1

Jones, D. N., \& Paulhus, D. L. (2009). Machiavellianism. In M. R. Leary \& R. H. Hoyle (Eds.), Handbook of individual differences in social behavior (pp. 93-108). Guilford Press.

Jones, D. N., \& Paulhus, D. L. (2011). Differentiating the Dark Triad within the interpersonal circumplex. In L. M. Horowitz \& S. Strack (Eds.), Handbook of interpersonal psychology: Theory, research, assessment, and therapeutic interventions (pp. 249-267). John Wiley \& Sons. 
Jones, D. N., \& Paulhus, D. L. (2014). Introducing the Short Dark Triad (SD3) a brief measure of dark personality traits. Assessment, 21, 28-41. https://doi.org/10.1177/1073191113514105

* Kajonius, P. J., \& Björkman, T. (2020). Individuals with Dark Traits have the ability but not the disposition to empathize. Personality and Individual Differences, 155. https://doi.org/10.1016/j.paid.2019.109716

* Kaufman, S. B., Yaden, D. B., Hyde, E., \& Tsukayama, E. (2019). The Light vs. Dark Triad of personality: Contrasting two very different profiles of human nature. Frontiers in Psychology, 10. https://doi.org/10.3389/fpsyg.2019.00467

Kirca, A. H., Hult, G. T. M., Deligonul, S., Perryy, M. Z., \& Cavusgil, S. T. (2012). A multilevel examination of the drivers of firm multinationality: A meta-analysis. Journal of Management, 38(2), 502-530. https://doi.org/10.1177/0149206310369177

* Law, M. K. H., Jackson, S. A., Aidman, E., Geiger, M., Olderbak, S., \& Kleitman, S. (2018). It's the deceiver, not the receiver: No individual differences when detecting deception in a foreign and a native language. PLoS ONE, 13(5). https://doi.org/10.1371/journal.pone.0196384

* Lee, S. A., \& Gibbons, J. A. (2017). The Dark Triad and compassion: Psychopathy and narcissism's unique connections to observed suffering. Personality and Individual Differences, 116, 336-342. https://doi.org/10.1016/j.paid.2017.05.010

* Lyons, M., Croft, A., Fairhurst, S., Varley, K., \& Wilson, C. (2017). Seeing through crocodile tears? Sex-specific associations between the Dark Triad traits and lie detection accuracy. Personality and Individual Differences, 113, 1-4. https://doi.org/10.1016/j.paid.2017.03.008

* Maheux-Caron, V., Gamache, D., Sellbom, M., Christian, E., Lussier, Y., \& Savard, C. (2020). French adaptation and validation of the expanded version of the three-factor Levenson 
Self-Report Psychopathy Scale. Assessment, 27(7), 1448-1462.

https://doi.org/10.1177/1073191118811607

Matsumoto, D., \& Ekman, P. (1989). American-Japanese cultural differences in judgments of facial expressions of emotion. Motivation and Emotion, 13, 143-157. https://doi.org/10.1007/BF00992959

* McIlwain, D., Evans, J., Caldis, E., Cicchini, F., Aronstan, A., Wright, A., \& Taylor, A. (2012). Strange moralities: Vicarious emotion and moral emotions in Machiavellian and psychopathic personality styles. In R. Langdon \& C. Mackenzie (Eds.), Macquarie monographs in cognitive science. Emotions, imagination, and moral reasoning (pp. 119148). Psychology Press. https://doi.org/10.1037/t01093-000

Miao, C., Humphrey, R. H., Qian, S., \& Pollack, J. M. (2019). The relationship between emotional intelligence and the Dark Triad personality traits: A meta-analytic review. Journal of Research in Personality, 78, 189-197. https://doi.org/10.1016/j.jrp.2018.12.004

Moher, D., Liberati, A., Tetzlaff, J., \& Altman, D. G. (2009). Preferred reporting items for systematic reviews and meta-analyses: The PRISMA statement. PLoS Medicine, 6(7), e1000097. https://doi.org/10.1371/journal.pmed.1000097

Monaghan, C., Bizumic, B., \& Sellbom, M. (2016). The role of Machiavellian views and tactics in psychopathology. Personality and Individual Differences, 94, 72-81. $\underline{\text { https://doi.org/10.1016/j.paid.2016.01.002 }}$

* Monaghan, C., Bizumic, B., \& Sellbom, M. (2018). Nomological network of two-dimensional Machiavellianism. Personality and Individual Differences, 130, 161-173. https://doi.org/10.1016/j.paid.2018.03.047

Monaghan, C., Bizumic, B., Williams, T., \& Sellbom, M. (2020). Two-dimensional 
Machiavellianism: Conceptualization, theory, and measurement of the views and tactics dimensions. Psychological Assessment, 32(3), 277-293. https://doi.org/10.1037/pas0000784

Moriarty, N., Stough, C., Tidmarsh, P., Eger, D., \& Dennison, S. (2001). Deficits in emotional intelligence underlying adolescent sex offending. Journal of Adolescence, 24(6), 743751. https://doi.org/10.1006/jado.2001.0441

Murphy, B. A., Costello, T. H., Watts, A. L., Cheong, Y. F., Berg, J. M., \& Lilienfeld, S. O. (2020). Strengths and weaknesses of two empathy measures: A comparison of the measurement precision, construct validity, and incremental validity of two multidimensional indices. Assessment, 27(2), 246-260. https://doi.org/10.1177/1073191118777636

Murphy, B. A., \& Lilienfeld, S. O. (2019). Are self-report cognitive empathy ratings valid proxies for cognitive empathy ability? Negligible meta-analytic relations with behavioral task performance. Psychological Assessment, 31(8), 1062-1072. https://doi.org/10.1037/pas0000732

Nagler, U. K. J., Reiter, K. J., Furtner, M. R., \& Rauthmann, J. F. (2014). Is there a “dark intelligence"? Emotional intelligence is used by dark personalities to emotionally manipulate others. Personality and Individual Differences, 65, 47-52. https://doi.org/10.1016/j.paid.2014.01.025

* Niemi, L., \& Young, L. (2017). Who sees what as fair? Mapping individual differences in valuation of reciprocity, charity, and impartiality. Social Justice Research, 30(4), 438449. https://doi.org/10.1007/s11211-017-0291-4

Nowicki, S., \& Duke, M. P. (1994). Individual differences in the nonverbal communication of affect: The diagnostic analysis of nonverbal accuracy scale. Journal of Nonverbal 
Behavior, 18, 9-35. https://doi.org/10.1007/BF02169077

O’Boyle, E. H., Forsyth, D., Banks, G. C., \& Story, P. A. (2013). A meta-analytic review of the Dark Triad-intelligence connection. Journal of Research in Personality, 47(6), 789-794. https://doi.org/10.1016/j.jrp.2013.08.001

* Paal, T., \& Bereczkei, T. (2007). Adult theory of mind, cooperation, Machiavellianism: The effect of mindreading on social relations. Personality and Individual Differences, 43(3), 541-551. https://doi.org/10.1016/j.paid.2006.12.021

* Pajevic, M., Vukosavljevic-Gvozden, T., Stevanovic, N., \& Neumann, C. S. (2018). The relationship between the Dark Tetrad and a two-dimensional view of empathy. Personality and Individual Differences, 123, 125-130. https://doi.org/10.1016/j.paid.2017.11.009

* Pátkai, G., \& Bereczkei, T. (2016). Machiavellianism and its relationship with theory of mind, emotional intelligence and emotion recognition. International Journal of Scientific and Research Publications, 6(9), 245-250.

Paulhus, D. L., \& Jones, D. N. (2015). Measures of dark personalities. In G. J. Boyle, D. H. Saklofske, \& G. Matthews (Eds.), Measures of personality and social psychological constructs (p. 562-594). Elsevier Academic Press. https://doi.org/10.1016/B978-0-12$\underline{386915-9.00020-6}$

Paulhus, D. L., \& Williams, K. M. (2002). The Dark Triad of personality: Narcissism, Machiavellianism and psychopathy. Journal of Research in Personality, 36(6), 556-563. https://doi.org/10.1016/S0092-6566(02)00505-6

Petrides, K. V., Frederickson, N., \& Furnham, A. (2004). The role of trait emotional intelligence in academic performance and deviant behavior at school. Personality and Individual Differences, 36, 277-293. https://doi.org/10.1016/S0191-8869(03)00084-9 
* Pilch, I. (2008). Machiavellianism, emotional intelligence and social competence: Are Machiavellians interpersonally skilled? Polish Psychological Bulletin, 39(3), 158-164. https://doi.org/10.2478/v10059-008-0017-4

Pursoo, T. (2013). Predicting reactive and proactive relational aggression in early adolescence as a function of individual differences in Machiavellianism, empathy, and emotion regulation [Doctoral Dissertation University of Ottawa]. https://doi.org/10.20381/RUOR$\underline{3218}$

* Puthillam, A., Karandikar, S., \& Kapoor, H. (2019). I see how you feel: How the Dark Triad recognizes emotions. Current Psychology. https://doi.org/10.1007/s12144-019-00359-x

Qualter, P., Barlow, A., \& Stylianou, M. S. (2011). Investigating the relationship between trait and ability emotional intelligence and theory of mind. British Journal of Developmental Psychology, 29(3), 437-454. https://doi.org/10.1348/026151010x502999

* Reeves Washer, S. R. (2008). Empathy: A proposed moderator to the relationship between Machiavellianism and social aggression in Hispanic and non-Hispanic children [Doctoral dissertation, University of Texas at Austin]. University of Texas Libraries. https://repositories.lib.utexas.edu/handle/2152/17728

* Reniers, R. L. E. P., Corcoran, R., Drake, R., Shryane, N. M., \& Völlm, B. A. (2011). The QCAE: A questionnaire of cognitive and affective empathy. Journal of Personality Assessment, 93(1), 84-95. https://doi.org/10.1080/00223891.2010.528484

* Rushton, J. P., Chrisjohn, R. D., \& Fekken, G. C. (1981). The altruistic personality and the selfreport altruism scale. Personality and Individual Differences, 2(4), 293-302. https://doi.org/10.1016/0191-8869(81)90084-2

Salovey, P., \& Mayer, J. D. (1994). Some final thoughts about personality and intelligence. In R. J. Sternberg \& P. Ruzgis (Eds.), Personality and intelligence (p. 303-318). Cambridge 
University Press.

* Schimmenti, A., Jonason, P. K., Passanisi, A., La Marca, L., Di Dio, N., \& Gervasi, A. M. (2019). Exploring the dark side of personality: Emotional awareness, empathy, and the Dark Triad traits in an Italian sample. Current Psychology, 38(1), 100-109. https://doi.org/10.1007/s12144-017-9588-6

* Schlegel, K., \& Mortillaro, M. (2019). The Geneva Emotional Competence Test (GECo): An ability measure of workplace emotional intelligence. Journal of Applied Psychology, 104(4), 559-580. https://doi.org/10.1037/apl0000365

* Schmitt, M., Gollwitzer, M., Maes, J., \& Arbach, D. (2005). Justice sensitivity: Assessment and location in the personality space. European Journal of Psychological Assessment, 21(3), 202-211. https://doi.org/10.1027/1015-5759.21.3.202

* Schmocker, D., Tanner, C., Katsarov, J., \& Christen, M. (2020). An advanced measure of moral sensitivity in business. European Journal of Psychological Assessment, 36(5), 864-873. https://doi.org/10.1027/1015-5759/a000564

Schutte, N. S., Malouff, J. M., Bobik, C., Conston, T., Greeson, C., \& Jedlicka, C. (2001). Emotional intelligence and interpersonal relations. Journal of Social Psychology, 141, 523-536. https://doi.org/10.1080/00224540109600569

* Simon, L. J., Francis, P. L., \& Lombardo, J. P. (1990). Sex, sex-role, and Machiavellianism as correlates of decoding ability. Perceptual and Motor Skills, 71(1), 243-247. https://doi.org/10.2466/PMS.71.4.243-247

* Stellwagen, K. K., \& Kerig, P. K. (2013). Dark Triad personality traits and theory of mind among school-age children. Personality and Individual Differences, 54(1), 123-127. https://doi.org/10.1016/j.paid.2012.08.019

Sutton, J., \& Keogh, E. (2001). Components of Machiavellian beliefs in children: Relationships 
with personality. Personality and Individual Differences, 30(1), 137-148. https://doi.org/10.1016/s0191-8869(00)00017-9

* Szabó, E., \& Bereczkei, T. (2017). Different paths to different strategies? Unique associations among facets of the Dark Triad, empathy, and trait emotional intelligence. Advances in Cognitive Psychology, 13(4), 306-313. https://doi.org/10.5709/acp-0230-7

* Szijjarto, L., \& Bereczkei, T. (2015). The Machiavellians' 'cool syndrome': They experience intensive feelings but have difficulties in expressing their emotions. Current Psychology, 34(2), 363-375. https://doi.org/10.1007/s12144-014-9262-1

* Tortoriello, G. K., \& Hart, W. (2019). Blurring the dichotomy of good and evil: The idiosyncratic helping strategies associated with unmitigated-agentic and unmitigatedcommunal personalities. European Journal of Personality, 33(6), 674-701. https://doi.org/10.1002/per.2223

* Trémolière, B., \& Djeriouat, H. (2016). The sadistic trait predicts minimization of intention and causal responsibility in moral judgment. Cognition, 146, 158-171. https://doi.org/10.1016/j.cognition.2015.09.014

* Turner, I. N., Foster, J. D., \& Webster, G. D. (2019). The Dark Triad's inverse relations with cognitive and emotional empathy: High-powered tests with multiple measures.

Personality and Individual Differences, 139, 1-6. https://doi.org/10.1016/j.paid.2018.10.030

Urbonaviciute, G., Hepper, E. G. (2020). When is narcissism associated with low empathy? A meta-analytic review. Journal of Research in Personality, 89, 104036. https://doi.org/10.1016/j.jrp.2020.104036

* Vachon, D. D., \& Lynam, D. R. (2016). Fixing the problem with empathy. Assessment, 23(2), 135-149. https://doi.org/10.1177/1073191114567941 
Vachon, D. D., Lynam, D. R., \& Johnson, J. A. (2014). The (non)relation between empathy and aggression: Surprising results from a meta-analysis. Psychological Bulletin, 140(3), 751773. https://doi.org/10.1037/a0035236

* van de Groep, S., Meuwese, R., Zanolie, K., Güroğlu, B., \& Crone, E. A. (2020).

Developmental changes and individual differences in trust and reciprocity in adolescence. Journal of Research on Adolescence, 30(S1), 192-208. https://doi.org/10.1111/jora.12459

* Vonk, J., Zeigler-Hill, V., Ewing, D., Mercer, S., \& Noser, A. E. (2015). Mindreading in the dark: Dark personality features and theory of mind. Personality and Individual Differences, 87, 50-54. https://doi.org/10.1016/j.paid.2015.07.025

* Wai, M., \& Tiliopoulos, N. (2012). The affective and cognitive empathic nature of the Dark Triad of personality. Personality and Individual Differences, 52(7), 794-799. https://doi.org/10.1016/j.paid.2012.01.008

* Wastell, C., \& Booth, A. (2003). Machiavellianism: An alexithymic perspective. Journal of Social and Clinical Psychology, 22(6), 730-744. https://doi.org/10.1521/jscp.22.6.730.22931

* Watson, P. J., Biderman, M. D., \& Sawrie, S. M. (1994). Empathy, sex role orientation, and narcissism. Sex Roles: A Journal of Research, 30(9-10), 701-723. https://doi.org/10.1007/BF01544671

* Watson, P. J., Morris, R. J., Hood, R. W., \& Folbrecht, J. (1990). Dependency, 'irrationality,' and community. Journal of Psychology and Theology, 18(4), 334-347. https://doi.org/10.1177/009164719001800404

* Wertag, A., \& Hanzec, I. (2016). Factor structure and psychometric properties of the Croatian short version of the Empathy Quotient. Suvremena Psihologija, 19(1), 101-110. https://doi.org/10.21465/2016-sp-191-09 
Wimmer, H., \& Perner, J. (1983). Beliefs about beliefs: Representation and constraining function of wrong beliefs in young children's understanding of deception. Cognition, 13(1), 103128. https://doi.org/10.1016/0010-0277(83)90004-5

* Wu, W., Su, Y., Huang, X., Liu, W., \& Jiang, X. (2020). The Dark Triad, moral disengagement, and social entrepreneurial intention: Moderating roles of empathic concern and perspective taking. Frontiers in Psychology, 11, 1520.

https://doi.org/10.3389/fpsyg.2020.01520

* Yuan, G., Liu, Z., \& An, Y. (2019). Machiavellianism, mindfulness and cyberbullying among Chinese junior high school students: The mediating role of empathy. Journal of Aggression, Maltreatment \& Trauma, 9, 1047-1058.

https://doi.org/10.1080/10926771.2019.1667467

* Zirenko, M., Kornilova, T., Qiuqi, Z., \& Izmailova, A. (2021). Personality regulation of decisions on physical distancing: Cross-cultural comparison (Russia, Azerbaijan, China). Personality and Individual Differences, 170, 110418.

https://doi.org/10.1016/j.paid.2020.110418 